\title{
Os Legados e Rugosidades do Ciclo Cafeeiro em Cornélio Procópio-PR: uma proposta didático-pedagógica com HQ'S
}

\author{
The Legacies and Roughness of the Coffee Cycle in Cornélio Procópio-PR: a \\ pedagogical didactic proposal with $H Q$ 'S
}

Los Legados y Rugosidades del Ciclo Cafetero en Cornelio Procópio-PR: una
propuesta didáctica pedagógica con HQ'S

\author{
Jhonatan da Silva Teixeira ${ }^{1}$ \\ Vanessa Maria Ludka² \\ Sérgio Augusto Pereira ${ }^{3}$
}

\begin{abstract}
RESUMO: O município de Cornélio Procópio possui legados inseridos em sua infraestrutura, como a ferrovia São Paulo-Paraná, a estação ferroviária e os armazéns do IBC. Esses legados deixados pela temporalidade do ciclo cafeeiro demonstram a influência na criação e organização espacial do município, que moldaram seu espaço conforme as necessidades desse ciclo. A presente pesquisa tem como objetivo compreender os principais legados deixados no município de Cornélio Procópio durante o ciclo cafeeiro no Paraná, apresentando uma proposta de material didático-pedagógico com o uso de histórias em quadrinhos. Metodologicamente, este trabalho foi realizado por meio de pesquisas bibliográficas, pautando-se em autores como Brasil (2014), Wachowicz (2001), Raffestin (1993), Castellar (2005), entre outros, que serviram como embasamento teórico para a discussão e compreensão dos conceitos, além de auxílio na elaboração da história em quadrinhos sobre Cornélio Procópio. Os legados observados diariamente na estrutura social e urbana do município, bem como sua linha férrea, são frutos do ciclo cafeeiro, que trouxe influências para o desenvolvimento do município, expressas em seu território no transcorrer das épocas, que pode ser analisado e compreendido. Nesta perspectiva, a história em quadrinhos auxilia na compreensão de forma lúdica dessas análises.
\end{abstract}

PALAVRAS-CHAVE: Cornélio Procópio-PR. Ciclo cafeeiro. Legados no território. História em quadrinhos. Material didático-pedagógico.

ABSTRACT: The Cornélio Procópio city contains legacies inserted on its infrastructure, as the railway São Paulo - Paraná, railway station and the warehouse of IBC. These legacies left by the time of coffee cycle where it is demonstrated the influence of it on the creation and spatial organization of the city, that formed its space according to the needs of this coffee cycle. Therefore, the present research

\footnotetext{
1 Universidade Estadual Norte do Paraná, PR 160, Km 0 (saída para Leópolis). CEP 86300-000 Cornélio Procópio - Paraná - Brasil. jhonatansilvateixeira23@gmail.com.

2 Universidade Estadual Norte do Paraná, PR 160, Km 0 (saída para Leópolis). CEP 86300-000 Cornélio Procópio - Paraná - Brasil. vanessaludka@gmail.com.

${ }^{3}$ Universidade Estadual de Londrina. Rodovia Celso Garcia Cid - Pr 445 Km 380 Cx. Postal 10.011 - Campus Universitário, PR, 86057-970. sergioaugustopereira018@gmail.com.
} 
has as main aim to understand the main legacies left in the city of Cornélio Procópio during the coffee cycle in Paraná, presenting a propose through this pedagogical didactic material through cartoons. Methodologically, this work was done through bibliographical means based on authors like Brazil (2014), Wachowicz (2001), Raffestin (1993), Castellar (2005), and others that served as theoretical basis for the discussion and understanding of concepts, beyond the support of cartoons elaboration about Cornélio Procópio. The legacies observed daily in the social and urban structure of the municipality, as its railroad, are fruits of the coffee cycle, which has brought certain influences to the development of the municipality, these being expressed in its territory in the course of the epochs, where it can be analysed and understood. From this perspective, the comic strip helps in the playful understanding of these analyses.

KEYWORDS: Cornélio Procópio-PR. Coffee cycle. Territory Legacy. Comic-Book Story. Pedagogical didactic material.

RESUMEN: El municipio de Cornélio Procópio posee legados insertados en su infraestructura, como el ferrocarril São Paulo - Paraná, estación ferroviaria y los almazenes del IBC. Estos legados dejados por la temporalidad del ciclo cafetero donde demuestran la influencia de éste en la creación y organización espacial del municipio, que moldearon su espacio según sus necesidades en este ciclo cafetero. Por tanto la presente investigación tiene como objetivo comprender los principales legados dejados en el municipio de Cornélio Procópio durante el ciclo cafetero en el Paraná, presentando por medio de esta una propuesta de material didáctico pedagógico, por medio de historias en cómics. Metodológicamente este trabajo fue realizado por medio de investigaciones bibliográficas, pautando en autores como Brasil (2014), Wachowicz (2001), Raffestin (1993), Castellar (2005), entre otros que sirvieron como base teórica para la discusión y comprensión de los conceptos, además de auxilio en la elaboración de la historia en comics sobre Cornélio Procópio. Los legados observados diariamente en la estructura social y urbana del municipio, como su línea férrea, son frutos del ciclo cafetero, que trajo ciertas influencias para el desarrollo del municipio, éstas quedando expresadas en su territorio en el transcurso de las épocas, donde puede ser analizado y comprendido. El cual en esta perspectiva el cómic auxilia en la comprensión de forma lúdica de estos análisis.

PALABRAS-CLAVES: Cornélio Procópio-PR. Ciclo cafetero. Legados en el territorio. Historias en cómics. Material didáctico pedagógico.

\section{INTRODUÇÃO}

O município de Cornélio Procópio possui legados históricos oriundos do ciclo cafeeiro, no qual as construções originais foram arquitetadas entre os anos de 1930 e 1970, tendo como resultados as impressões de marcas do passado no território ípio e que podem ser observadas na contemporaneidade pela sociedade.

Sendo assim, o presente artigo tem como objetivo compreender os principais legados no município de Cornélio Procópio oriundos do ciclo cafeeiro no Paraná, apresentando uma proposta de material didático-pedagógico com o uso de histórias em quadrinhos. Metodologicamente este artigo realizou-se por meio de pesquisa bibliográfica, levantamento de dados em órgãos governamentais e trabalho de campo, além da elaboração de uma história em quadrinhos sobre Cornélio Procópio-PR.

Este artigo foi dividido em três partes. Na primeira parte se discutiu o conceito de território e a aplicação desse conceito na realização da pesquisa, buscando seguir o 
desenvolvimento epistemológico pelo decorrer dos anos e elucidar os "legados" e "rugosidades" aqui discutidos. Na segunda, dissertou-se a respeito do contexto do ciclo cafeeiro no Paraná e como isso influenciou na criação e organização de Cornélio Procópio, resultando em legados encontrados na infraestrutura social e urbana. Na última e terceira parte, tratou-se sobre a utilização de histórias em quadrinhos (HQ's) como recurso pedagógico para o ensino de forma lúdica, apresentando uma história em quadrinhos e a importância da utilização desse recurso pedagógico nas aulas de Geografia.

Assim, apresentou-se como premissa que os legados observados diariamente na estrutura social e urbana de Cornélio Procópio, bem como a linha férrea (que corta a cidade ao meio), não estão lá por acaso, pois são frutos de uma temporalidade e do ciclo cafeeiro no Paraná, o qual trouxe para o município certo desenvolvimento e notoriedade, que ficou expresso em seu território no transcorrer das épocas, podendo ser analisado e compreendido ao invés de somente observado sem nenhum sentido. E, nessa perspectiva, a história em quadrinhos se apresenta como uma ferramenta que auxilia na análise e compreensão dos objetos de forma lúdica.

\section{CARACTERIZAÇÃO DA ÁREA DE ESTUDO}

O município de Cornélio Procópio encontra-se localizado na macrorregião Sul do Brasil, no Estado do Paraná, na mesorregião do Norte Pioneiro do Paraná e mais precisamente na microrregião de Cornélio Procópio. Os municípios limítrofes de Cornélio Procópio são: a nordeste, o município de Santa Mariana, a leste os municípios de Bandeirantes, Santa Amélia e Ribeirão do Pinhal, a sul fica o município de Nova Fátima, a sudoeste o município de Nova América da Colina, a oeste fica Uraí e a noroeste, o município de Leópolis (Figura 1).

Segundo o Caderno do Ipardes (abril de 2019), com base nos dados do IBGE, 2017, o município de Cornélio Procópio possuía uma população de 46.928 em 2010, sendo que 44.308 habitantes residiam na zona urbana e 2.620 habitantes na zona rural. A estimativa da população para o ano de 2018 ficou em 47.847 habitantes, ou seja, estima-se que houve um aumento na população. O município possui uma área territorial de 637,946 quilômetros quadrados (IPARDES, 2019).

Em relação aos aspectos físicos, o município de Cornélio Procópio está localizado sob o Terceiro Planalto paranaense, que também é conhecido como Planalto de Guarapuava, sendo terrenos datados da era mesozoica, constituído por estratos de arenitos São Bento Inferior ou Botucatu com derrames de lavas basálticas. O terceiro planalto é limitado pela Escarpa Triássico-Jurássico, estendendo-se até o Oeste do Rio Paraná. A rocha 
predominante na região do município é o Basalto, rocha magmática vulcânica, que deu origem à terra roxa (SCORTEGAGNA, 2005).

Figura 1 - Mapa de localização de Cornélio Procópio, 2018

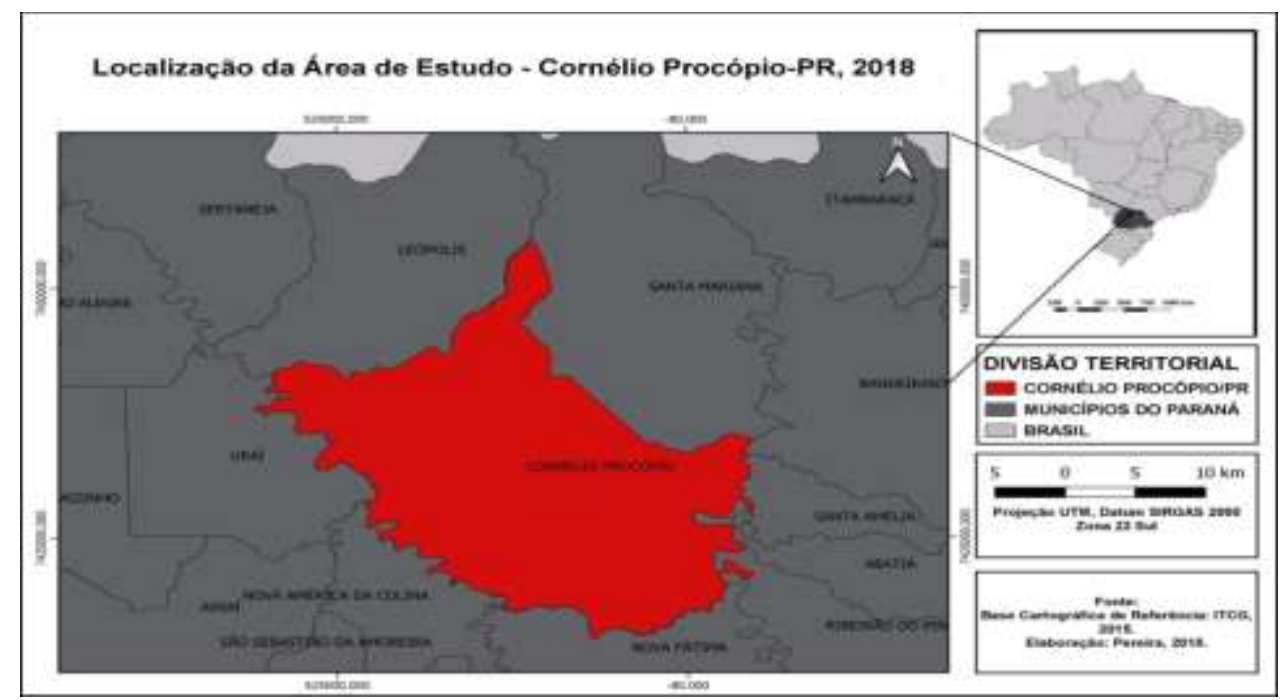

Elaborado por: Pereira (2018).

O recorte espacial desse estudo faz parte da Bacia Hidrográfica do rio Paranapanema que abrange com seus afluentes à margem sul, cerca de 55.530 quilômetros quadrados. $O$ rio Paranapanema forma a divisa entre os Estados do Paraná e São Paulo numa extensão de cerca de 390 quilômetros desde o rio Itararé até o rio Paraná.

Segundo a classificação de Köppen, a área de estudo apresenta um clima subtropical úmido mesotérmico, com verões quentes e invernos com poucas geadas, sem uma estação seca. A temperatura média do mês mais quente fica superior a $22^{\circ} \mathrm{C}$ e a do mês mais frio fica inferior a $18^{\circ} \mathrm{C}$ (MARQUES, 2005).

Ainda de acordo com Marques (2005), a vegetação que compõe a área de estudo é a floresta tropical, que ocupa a parte norte do terceiro planalto paranaense, na qual se desenvolveu uma vasta variedade de espécies de plantas e árvores, sobre os solos férteis da terra roxa.

\section{CONCEPÇÃO E LEGADO DO TERRITÓRIO PROCOPENSE}

O conceito de território torna explicativos os componentes formadores do espaço, como as relações sociais e organização, a fim de salientar aspectos que o construíram, deixando marcas materiais e imateriais como legados de certos períodos históricos, como se observa na formação do município de Cornélio Procópio-PR durante o ciclo cafeeiro. 
O conceito emerge nas pesquisas de Ratzel (1990), quando o pesquisador discute a relação do Estado com a sociedade. Dessa maneira, ressalta aspectos de como a sociedade com suas dinâmicas de relacionamento e apropriação do espaço constroem um determinado território. "[...] o território se apoia no espaço, mas não é o espaço. É uma produção, a partir do espaço. Ora, a produção, por causa de todas as relações que envolve, se inscreve num campo de poder. Produzir uma representação do espaço já é uma apropriação" (RAFFESTIN, 1993, p. 144).

A partir do momento em que o espaço onde se localiza Cornélio Procópio foi apropriado para fins de criação de um município, esse espaço contou com agentes de práticas de poder para inserção de pessoas. Essas práticas de poder geraram ocupações que futuramente vieram a possuir ações políticas que foram aspectos auxiliadores para a emancipação desse território em povoado, distrito e no próprio município de Cornélio Procópio, o qual possui marcas realizadas sobre o território durante o ciclo cafeeiro, que se perpetuaram pelos anos.

Ao se analisar o contexto de construção do município, percebe-se que Cornélio Procópio passou pelas características sobre as quais disserta Saquet (2011), tendo ocorrido divisões políticas, sendo esta, de certa forma, uma forma de poder que dá origem ao território. Com a vinda de muitos imigrantes para o Norte do Paraná em busca de melhores condições, partes dessas terras foram sendo adquiridas por esses imigrantes para se estabelecerem, causando outra forma de poder - de posse - iniciando, dessa forma, as primeiras ocupações territoriais, urbanas e rurais. Por consequência dessas formas de se empregar um espaço, produzindo um território a partir destas ações, gerou-se uma conotação de pertencimento à qual tende a exprimir suas manifestações sobre o território.

O território não é apenas um conceito que abarca as relações naturais e sociais postas umas sobre as outras, sem possuir nenhum nexo, mas é entendido como "um território usado", dotado de identidade por parte de seus confeccionistas, sendo, dessa forma, "[...] o fundamento do trabalho; lugar da residência, das trocas materiais e espirituais e do exercício da vida [...]" (SANTOS, 1999, p. 8), o que torna possível observar as expressões da sociedade em determinados períodos históricos, tal como o ciclo cafeeiro.

Para Haesbaert (2004, p. 95-96), o conceito de território, em seu aspecto de poder e apropriação de uma sociedade-espaço, trata de um processo "[...] contínuo que vai da dominação político-econômica mais 'concreta' e 'funcional' à apropriação mais subjetiva e/ou "cultural-simbólica". O primeiro se refere às dinâmicas de produção de um determinado território pelo viés econômico, como da matéria cafeeira e sua comercialização no Norte do Paraná, e o segundo das produções simbólicas, sendo o pertencimento da sociedade pelo território que gerou o município de Cornélio Procópio. Ambas as formas de territorialização ocasionaram impressões no contexto cafeeiro sobre o território procopense. 
O geógrafo brasileiro Milton Santos disserta sobre as configurações do território, o qual é caracterizado pelas técnicas, pelos meios de produção, pelos objetos, pelas coisas, pelo conjunto territorial e pela dialética do território com o espaço. Esse território encontra-se inserido em um espaço, o qual possui determinados "legados" sendo compreendidos, no sentido da palavra, como algo transmitido, que para Milton Santos são "rugosidades".

Chamemos de rugosidades ao que fica do passado como forma, espaço construído, paisagem, o que resta do processo de supressão, acumulação, superposição, com que as coisas se substituem e acumulam em todos os lugares. As rugosidades se apresentam como formas isoladas ou como arranjos (SANTOS, 2002, p. 140).

Para Santos, essas rugosidades ou legados tratam de uma coexistência no tempo presente, de feições moldadas em determinadas temporalidades, por meio de técnicas e manifestações da sociedade sobre o espaço. As rugosidades se mantêm no território com o passar dos anos, dando determinado significado e simbologia às estruturas assistidas, como os barracões da IBC (Instituto Brasileiro do Café) construídos no Paraná durante o ciclo cafeeiro, ou até mesmo à linha férrea São Paulo-Paraná, construída no mesmo período. Essas impressões no território são utilizadas como objetos de análise nesta pesquisa.

Na gênese do território de Cornélio Procópio, outrora conhecido como "Km 125", está a doação das terras, nas quais se localiza hoje o município, pelo Coronel Cornélio Procópio de Araújo Carvalho ao seu genro Francisco da Cunha Junqueira, que era casado com sua filha Maria Balbina Procópio Junqueira (BRASIL, 2014).

Francisco da Cunha Junqueira era proprietário da Gleba Laranjinha e da fazenda Santa Mariana, localizada no "Km 107". Quando a fazenda Santa Mariana teve contato com a linha férrea, que passava nas terras de Francisco, em acordo com a Companhia São Paulo-Paraná, criou-se uma estação e a nomearam de Santa Mariana, em homenagem a sua esposa, que no decorrer do tempo tornou-se município com a mesma denominação. O mesmo ocorreu quando a ferrovia chegou ao "Km 125", quando Francisco interviu para que o "Km 125" fosse nomeado com o nome de seu sogro "Cornélio Procópio" como uma forma de homenageá-lo (BRASIL, 2014).

As decisões tomadas durante o ciclo cafeeiro acarretaram diversas implicações na configuração do território do município que, segundo as necessidades e exigências desse período econômico cafeeiro, moldaram a estrutura de Cornélio Procópio. Essas estruturas, ao passar do tempo, continuaram inseridas na estrutura urbana e social do município, mas tomando novos usos, tornando-se espaços de rugosidades, sendo legados temporais assistidos na realidade contemporânea, passíveis de análises críticas remetendo ao passado não muito distante, mas com realidades diferentes. Essas análises e legados poderão ser conhecidos no item seguinte. 


\section{O CICLO CAFEEIRO E SEUS LEGADOS EM CORNÉLIO PROCÓPIO - PR}

A produção de café exibiu um protagonismo em determinada temporalidade histórica, pois o café já chegou a ser considerado "ouro verde" por sua significância na esfera econômica e de mercado no Brasil. Conforme dissertou Bragueto (2007), a frente pioneira, somada à cafeicultura, fez com que as terras do Norte Pioneiro do Paraná ganhassem importância, dando-Ihes um preço e transformando-as em mercadoria, auxiliando na comercialização dessas terras e posteriormente na aquisição por parte de novos compradores.

Assim como no Norte do Paraná, outras regiões do Brasil experimentaram os impactos e a influência do ciclo do café na formação socioespacial ou econômica de determinadas cidades do Brasil. Felippe Pessoa de Melo e Rosemeri Melo e Souza (2015) publicaram um artigo que põe em pauta essa discussão, com o trabalho intitulado "Reterritorialização do espaço agrário pernambucano, a partir de políticas públicas governamentais em GaranhunsPE: erradicação do café e implantação da bacia leiteira", em que se analisa a troca da cultura do café pela cultura do leite no município de Garanhuns-PE. Dessa forma, percebese, com esse exemplo, que esse fenômeno não se restringe apenas à região do Norte do Paraná.

O ciclo cafeeiro no Paraná teve início com a expansão da produção cafeeira de São Paulo, tendo sua gênese na exploração das terras do Norte do Paraná, iniciada por mineiros e paulistas que, juntamente com a expansão das linhas férreas na região do Norte do Paraná, realizaram diversas transformações na região em questão e em Cornélio Procópio.

Desse modo, na década de 1930, o Paraná tornou-se palco das maiores produções de café por conta de seus solos férteis, mais conhecidos como "terra roxa", o qual possui grande capacidade para a produção agrícola. A produção cafeeira paulista, visando o potencial de fertilidade dessas terras, iniciou o processo de expansão que originou as primeiras ocupações e colonização do Norte do Paraná (LUZ, 1997, p. 18):

Apesar de possuir terras férteis, o Norte do Paraná teve dificuldades no seu desenvolvimento econômico por conta da sua localização e por ainda não possuir infraestrutura para escoar sua produção de café, o que dificultou a comercialização, sendo que já se produzia mais do que em São Paulo. Sendo assim, os próprios cafeicultores do Norte do Paraná começaram a investir e criar condições para a ampliação da comercialização por meio de infraestrutura, comércio e principalmente ferrovias (BRAGUETO, 2007). Isso fez com que o estado se desenvolvesse e elevasse a produção cafeeira, resultando também no desenvolvimento da região. A partir disso, começou o loteamento de terras e construção de estradas vicinais, rodovias e ampliação da estrada de 
ferro, sendo que essas características também são apresentadas na formação de muitos municípios do Norte de Paraná, assim como em Cornélio Procópio.

Luz (1997) dissertou que, apesar das terras roxas de grande fertilidade e a procura no cultivo de café, a Companhia de Terras Norte do Paraná, responsável pela colonização do Norte do Paraná, promoveu uma colonização de pequenas propriedades, favorecendo, assim, a existência de uma população rural numerosa. Na região de Cornélio Procópio, "[...] de uma maneira geral, após 1929 as terras incorporadas à agricultura o foram a partir de loteamentos voltados as pequenas e médias propriedades" (FRESCA, 2007, p. 215).

O município de Cornélio Procópio tem a sua gênese no ciclo cafeeiro do Paraná e na estrada de ferro São Paulo-Paraná, que se mostraram impulsionadores do desenvolvimento do futuro município. Conforme esse desenvolvimento se ampliava, produzia impressões na estrutura urbana e social, as quais, com passar dos tempos, ficaram cristalizadas, tornandose legados de épocas pretéritas, permitindo a observação das rugosidades do espaço urbano de períodos passados. No sentido material, esses legados podem ser os armazéns do IBC, e no âmbito imaterial, um território que se tornou núcleo de serviços no Norte Pioneiro (WACHOWICZ, 2001).

Francisco e sua esposa Maria foram os primeiros que realizaram loteamentos no espaço do município, sendo concretizados pela firma "Paiva \& Moreira". Esses loteamentos, realizados tanto pela "Paiva \& Moreira" quanto pela Companhia de Terras Norte do Paraná, ocorreram por todo o Norte do Paraná e auxiliaram na criação de diversos municípios. Simões de Paula (2007, p. 27) ressalta a importância das propagandas da Companhia de Terras Norte do Paraná, que "[...] indiretamente beneficiou o progresso e o povoamento da região de Cornélio Procópio", assim como a povoação de todo o Norte do Paraná (COMPANHIA MELHORAMENTOS DO NORTE DO PARANÁ, 1975).

Posteriormente, a instalação da estação ferroviária, que se tornou um legado histórico do município, "[...] facilitou o crescimento do núcleo, que acabou sendo denominado Cornélio Procópio" (WACHOWICZ, 2001, p. 264).

\begin{abstract}
A partir de então expandiu o número de núcleos urbanos fundados: de leste para oeste tivemos em 1927, Andirá; em 1929, Bandeirantes; em 1924, Cornélio Procópio; Itambaracá em 1922 [...]. O ato da fundação dos núcleos urbanos ainda estava vinculado à doação de terras para a futura cidade por um fazendeiro, mas a sua localização já estava mais orientada à presença da ferrovia, inclusive o gerando o desaparecimento de núcleos fundados anteriormente a extensão dos trilhos (FRESCA, 2007, p. 216).
\end{abstract}

Assim, com passar do tempo, o "Km 125" tornou-se "povoado de Cornélio Procópio", patrimônio pertencente a Cambará. Em seguida, distrito de Bandeirantes em 1936, tendo suas primeiras mobilizações para emancipação em 1937. No dia 18 de janeiro de 1938, a 
sua emancipação se concretizou, sob o decreto no 6.612. Bandeirantes foi rebaixado para a categoria de distrito de Cornélio Procópio (IBGE, 2017).

Simões de Paula (2007) disserta que o avanço da estrada de ferro e o desenvolvimento da região levaram Cornélio Procópio a se tornar uma espécie de núcleo regional para realização de diversos serviços. A ferrovia São Paulo-Paraná auxiliou na questão do povoamento da região Norte do Paraná e consequentemente de Cornélio Procópio, uma vez que o município se encontrava em uma área de produção cafeeira e já possuía serviços como médicos, serrarias, máquinas de beneficiamento de café, farmácias, cinema, entre outros.

Essa distribuição de serviços e cargas foi maior nos períodos de 1950 e 1960, em que Cornélio Procópio chegou a produzir "200 sacas de café em coco por mil pés de café", o que resultou a Cornélio Procópio o título de "Capital Mundial do Café", sendo um título não oficial, apenas simbólico, como espécie de desígnio para o maior produtor de café durante um ano (BRASIL, 2014, p. 16).

A ferrovia influenciou no desenvolvimento de Cornélio Procópio, não somente pelos seus serviços ofertados, mas também pela utilização da "Maria Fumaça", que chamava a atenção da população residente, ofertando serviços na área de transporte de passageiros e de cargas.

O legado deixado pela ferrovia no município de Cornélio Procópio está explícito, pois até hoje se encontram as rugosidades, ou seja, as marcas deixadas pela temporalidade como a linha férrea SP-PR. Outras estruturas ligadas à linha férrea podem ser observadas, adquirindo, no presente, outras utilidades, o que justifica o conceito de rugosidade discutido pelo autor Milton Santos. Dessa forma, observa-se na figura 2 a estação ferroviária, que outrora foi utilizada para embarque e desembarque de passageiros e hoje assume uma nova funcionalidade: a de Museu de História Natural.

A estação ferroviária de Cornélio Procópio (Figura 2) foi construída em 1930 e era utilizada para parada e pontos de desvio da ferrovia SP-PR. Ela passou por reformas nos anos subsequentes (conforme se observa nas fotos da Figura 2), sendo ampliada, e posteriormente se tornou o prédio do Museu de História Natural do município, sendo uma estrutura pública que apenas conserva acervos de animais empalhados.

Conotam-se também como uma das rugosidades do município os armazéns do IBC, que na atualidade estão concedidos para outros fins à UTFPR (Universidade Tecnológica Federal do Paraná) (Figura 3). A construção ainda permanece a original desde a fundação do município, e por diversas pessoas passarem pelos armazéns do IBC sem ter o conhecimento desse fato, ressalta-se a importância de se observar com atenção certas estruturas urbanas que fizeram e fazem parte da construção socioespacial do município. 
Figura 2 - Estação Ferroviária Cornélio Procópio (primeira foto); Museu de História Natural (segunda foto)

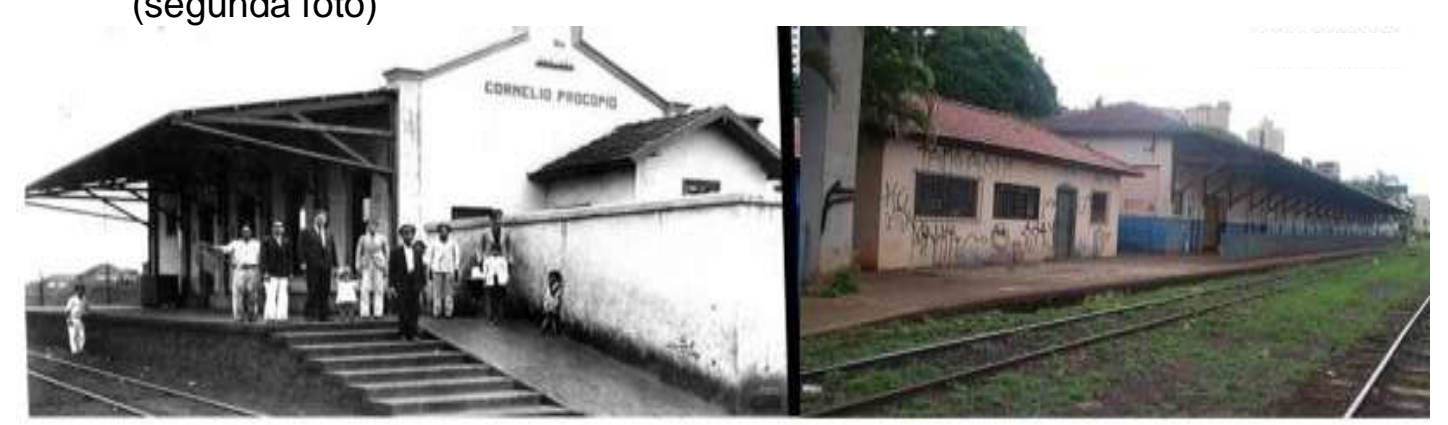

Fonte: Brasil, 2014; e Autoria: Teixeira, 2018.

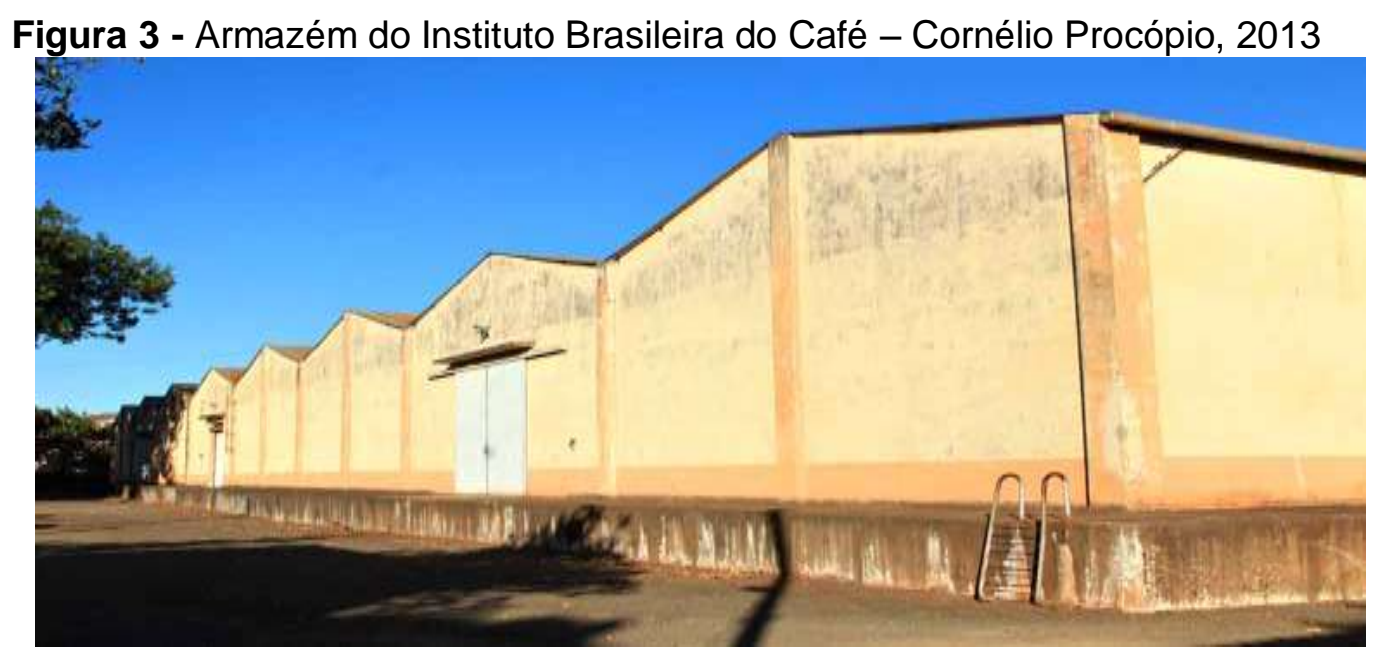

Fonte: Carneiro (2018).

Os armazéns do antigo Instituto Brasileiro do Café (IBC) foram construídos em diversas cidades do Paraná, com o intuito de estocar a produção de café na época. Com o desmanche do Instituto pelo presidente Fernando Collor, esses armazéns terminaram por ficar sem utilidade e se tornaram estruturas públicas que remetem ao período do auge do café na região, tornando-se rugosidades referentes ao ciclo cafeeiro (CABRAL; SÁ, 2009). Em Cornélio Procópio, esses armazéns foram concedidos à UTFPR para serem reutilizados na criação de complexos para estudos, mas por questões administrativas da UTFPR, os armazéns encontram-se sem utilização (CARNEIRO, 2018).

Ao tratar da conjuntura imaterial do território, encontram-se os serviços regionais concentrados em Cornélio Procópio, tornando-o um núcleo de concentração de serviços por conta de sua notoriedade durante o ciclo cafeeiro no Paraná e também na indústria Cia. Iguaçu Café Solúvel, que se instalou no município no fim do período do ciclo cafeeiro. Assim, esses serviços de comercialização e industrialização do café, pejados de certa simbologia histórica para o município que ainda hoje possui finalidades diferentes, são carregados de cargas históricas que remetem ao passado, apresentando-se como legados inseridos na infraestrutura urbana do município, originados do ciclo cafeeiro. 
Dando seguimento à análise e à reflexão dos legados oriundos do ciclo cafeeiro no município de Cornélio Procópio, sentiu-se necessário fazer um breve apontamento sobre a produção de café a partir da década de 1960 e posteriormente ao seu declínio, nos anos subsequentes à década de 1970.

Em 1969 o "[...] café representava mais de um terço das exportações brasileiras, ao passo que em 1975 não superava $7 \%$ na pauta de exportações, era o fim de um ciclo" (OLIVEIRA, 2005, p. 221). Na década de 1970 o café entrou em declínio por conta de fatores políticos, jurídicos, econômicos e por causa das geadas ocorridas, fazendo com que deixasse de ser rentável e consequentemente fosse retirado da maior parte do Norte do Paraná. Dessa forma, causou uma migração da área rural para a área urbana do município, sendo que essa migração ocorreu na grande maioria dos municípios do Norte do Paraná.

Os serviços ofertados pelo município também mudaram a partir de 1970. Cornélio Procópio deixou de ser exclusivamente dependente da economia agrícola e passou a ter sua economia baseada também em setores de serviços e indústrias como a Cia. Iguaçu Café Solúvel, a Kanebo Silk do Brasil S.A., entre outras (BRASIL, 2014; VASCONCELOS; PIRES; LUZ, 2014).

Essas empresas receberam o aspecto de legados, mesmo a Cia Iguaçu Café Solúvel ainda estando em funcionamento, sendo marcas expressas nas estruturas urbanas do município, caracterizando-se como rugosidades temporais. As construções como a estação ferroviária e os armazéns da IBC são legados que permanecem alocados nos mesmos espaços de outrora, mas com utilidades, na contemporaneidade, diferentes das originais.

Santos (2002) disserta que as rugosidades se manifestam como formas isoladas ou como arranjos. Elas nos trazem os restos de divisões do trabalho já passadas, em todas as escalas, os restos dos tipos do capital utilizados e suas combinações técnicas e sociais com o trabalho. É nesse sentido que a "Maria Fumaça" se insere, pois mesmo não sendo a locomotiva original, encontra-se inserida como objeto decorativo cultural que expressa a sua carga simbólica histórica para o município, estando alocada em frente ao Centro de Eventos de Cornélio Procópio (Figura 4).

A locomotiva "Maria Fumaça" foi inaugurada em 1930 (Figura 4), realizando o trajeto Cambará-Cornélio Procópio - PR, sendo utilizada para o transporte de cargas e de pessoas. Ela acabou por não ser mais utilizada para transporte de passageiros e hoje é usada somente para o transporte de cargas.

Outro legado do ciclo cafeeiro é a linha férrea SP-PR que, segundo Dorfmund (1962) e a Companhia Melhoramentos Norte do Paraná (1975), foi construída por um grupo paulista ligando os trechos da ferrovia Sorocabana em Ourinhos até o rio Cinza, e no ano de 1928 foi adquirida pela Companhia Terras do Norte do Paraná, que realizou a construção de diversas estações ferroviárias, sendo uma dessas, a do "Km 125", trecho correspondente a 
Cornélio Procópio. A estação do "Km 125" era utilizada para transporte de cargas e também de passageiros, tratando-se da primeira rugosidade cristalizada no território de Cornélio Procópio-PR, e teve modificações em seu uso com o passar do tempo.

Figura 4 - Maria Fumaça, trecho Cambará-Cornélio Procópio (primeira foto); Maria Fumaça localizada no centro de eventos (segunda foto)

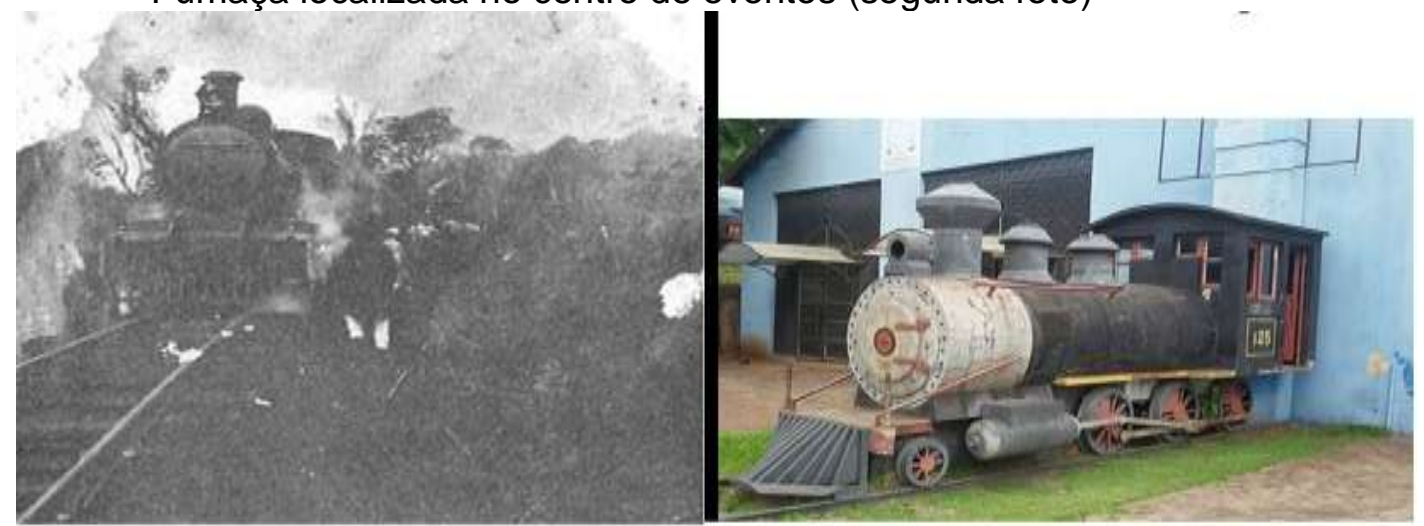

Fonte: Brasil, 2014; e Autoria: Teixeira, 2018.

As mudanças ocorridas na linha férrea não foram tão drásticas como no caso dos outros exemplos de rugosidades que se apresentam no município. A linha férrea ainda está transportando mercadorias, como grãos de soja, milho, óleos industrializados, combustíveis, madeira, celulose e papel, entre outras cargas, e não está mais transportando passageiros. Hoje, sua concessão está sob a responsabilidade da empresa ALL (América Latina Logística S. A.), e há em Cornélio Procópio um dos pontos de parada para a troca de maquinista e manutenção das locomotivas e das cargas. Esse trecho corresponde ao chamado "malha sul", transportando dos estados ao Sul do Brasil (Rio Grande do Sul, Santa Catarina) para sua sede em Curitiba e até São Paulo, onde se conecta com outra malha ferroviária da empresa.

Essa ferrovia mostra-se como o primeiro legado IPARDído no município, trazendo consigo diversas transformações, além de influenciar na organização urbana. A ferrovia corta a cidade ao meio e o processo de habitação e desenvolvimento urbano da cidade se deu em seu entorno. Assim, ressalta-se a sua importância para o município de Cornélio Procópio - PR (BRASIL, 2014; WACHOWICZ, 2001).

Porém, a problemática que se mostra é a falta de conhecimento referente a esses legados históricos por parte da comunidade que apenas observa essas estruturas sem de fato compreender o caráter geográfico e histórico que elas têm. Destarte, é importante que pesquisadores e professores levem esses temas para a discussão nas universidades, nas escolas, nos bairros, nas comunidades, entre outros espaços, para que esses legados e rugosidades possam ser observados e assim, proporcionar aos discentes a aquisição dos 
conhecimentos neles inseridos para que os alunos compreendam como se formou o espaço em que residem e como isso influencia no seu cotidiano.

\section{A UTILIZAÇÃO DE HQ'S COMO MATERIAL DIDÁTICO-PEDAGÓGICO NA COMPREENSÃO DOS LEGADOS DE CORNÉLIO PROCÓPIO}

A dinâmica de configuração do território de Cornélio Procópio e as impressões que ficaram nele inseridas, não são facilmente analisadas geograficamente pela população não acadêmica, ainda mais se abordada com jovens do ensino médio, que por muitas vezes consideram enfadonhas tais análises críticas por conta do avanço tecnológico que permeia o cotidiano do discente e que se sobressai com relação à atenção. Desta forma, optou-se a utilização de histórias em quadrinhos (HQ's), como uma forma de se realizar análises críticas de maneira prazerosa com os alunos, pois o conteúdo abordado está intrínseco nas HQ'S, apresentando-o de modo explicativo e com outras modalidades de linguagem (verbal e não verbal), auxiliando na fixação e compreensão das rugosidades oriundas do ciclo cafeeiro.

O ensino de Geografia tem como finalidade levar os alunos a pensar e refletir criticamente sobre conceitos de espaço, território, lugar, paisagem e região, entre outros, além de relacionar tais conceitos com assuntos do cotidiano dos discentes, levando-os a criar pensamentos críticos acerca da sociedade e realidade vivida. Callai (2012, p. 86) discorre que "[...] o aluno é um sujeito que vive nesse lugar e que, como tal, deve compreender sua identidade e pertencimento, precisa-se reconhecer como alguém que pode interferir em sua vida e na construção da sociedade em que vive".

Em outros termos, o conhecimento a ser alcançado no ensino, na perspectiva de uma Geografia Crítica, não se localiza no professor ou na ciência a ser "ensinada" ou vulgarizada, e sim no real, no meio onde o aluno e professor estão situados e é fruto da práxis coletiva dos grupos sociais. Integrar o educando no meio significa deixá-lo descobrir que pode tornar-se sujeito na história (VESENTINI, 2003, p. 37).

Dessa forma, é importante pensar a Geografia em relação aos seus aspectos teóricometodológicos, colocando o aluno como sujeito e como centro da discussão do processo de ensino, abordando também a sua realidade social, para que, a partir desse pressuposto, 0 conhecimento possa ser construído (CAVALCANTI, 2008). "A aprendizagem deve ocorrer de forma espontânea agregando significado a realidade do aprendiz, mas sempre o conectando com outros cenários" (MELO; MELO E SOUZA, 2018, p. 6).

A Geografia por possuir um caráter teórico em sua epistemologia é vista como monótona perante aos alunos e isso dificulta a relação de ensino-aprendizagem dos 
discentes. Isso tem a necessidade de ser revisto, pois se trata de um conhecimento real do cotidiano do aluno (CASTELLAR, 2005).

Diferentes estratégias de ensino, métodos e metodologias são abordadas para se atrair a atenção do aluno, sendo que cada vez mais a inserção da tecnologia tem competido com o professor pela atenção dos educandos. Uma das estratégias que pode ser utilizada para atrair a atenção dos discentes é o uso de metodologias com o emprego do lúdico aplicado ao ensino de Geografia, como mudanças na rotina das aulas e o uso de produtos pedagógicos.

Nesse sentido, podem-se utilizar as HQ'S, que além de serem um tipo textual, são formas de se abordar conteúdos teóricos e também conteúdos do cotidiano dos alunos, de maneira que atrai a atenção dos discentes por possuírem linguagens verbais e não verbais. "Uma habilidade estudada, que pode ser aprendida, que se baseia no emprego imaginativo do conhecimento da ciência e da linguagem, assim como a habilidade de retratar ou caricaturar e de manejar as ferramentas do desenho" (EISNER, 1995, p. 144).

Essa arte de sequência histórica em quadros auxilia o desenvolvimento do aluno, pois possui uma leitura tanto verbal como não verbal, o que leva o aluno a analisar por completo o quadro e o contexto expresso ali (EISNER, 1995), indo ao encontro dos estudos geográficos, pois ao analisar ou reproduzir essas histórias, o aluno tende a observar o contexto, como a paisagem expressa, que se torna trabalho geográfico por excelência, além de possuir as contribuições críticas em suas construções e análises.

Para Maccloud (1995), essas imagens expressas em sequência têm por finalidade trazer informações com a resposta do espectador ou gerar esta resposta referente a assuntos de sua realidade. Dessa maneira, serve como produto estratégico para ensinar a história de Cornélio Procópio no contexto do ciclo cafeeiro, apresentando os legados que ficaram expressos na infraestrutura social e urbana do município em questão, que os discentes irão conhecer de forma lúdica e analisar de forma crítica.

Nessa perspectiva, a contribuição nos estudos dos tempos históricos e como os acontecimentos passados influenciaram nas dinâmicas de formação de diversos espaços e territórios podem ser observados nas Figuras 5, 6 e 7, as quais retratam o ensino desse processo por meio de um produto didático-pedagógico sobre os legados de Cornélio Procópio-PR, realizado para fins exclusivamente desta pesquisa.

Essa HQ’s pode ser aplicada em qualquer série, mas recomenda-se que sejam as séries do ensino fundamental II, ou seja, do sexto ao nono ano. Nesta pesquisa não foi possível aplicar essa HQ`s, porém a intenção é que futuramente possa-se elaborar uma proposta didática com o seu uso e executá-la em sala de aula, para assim gerar resultados, e posteriormente expô-los em artigos futuros. 
Figura 5 - Primeira página HQ's: "Vivi, a maquinista, e os legados do tempo de Cornélio Procópio"
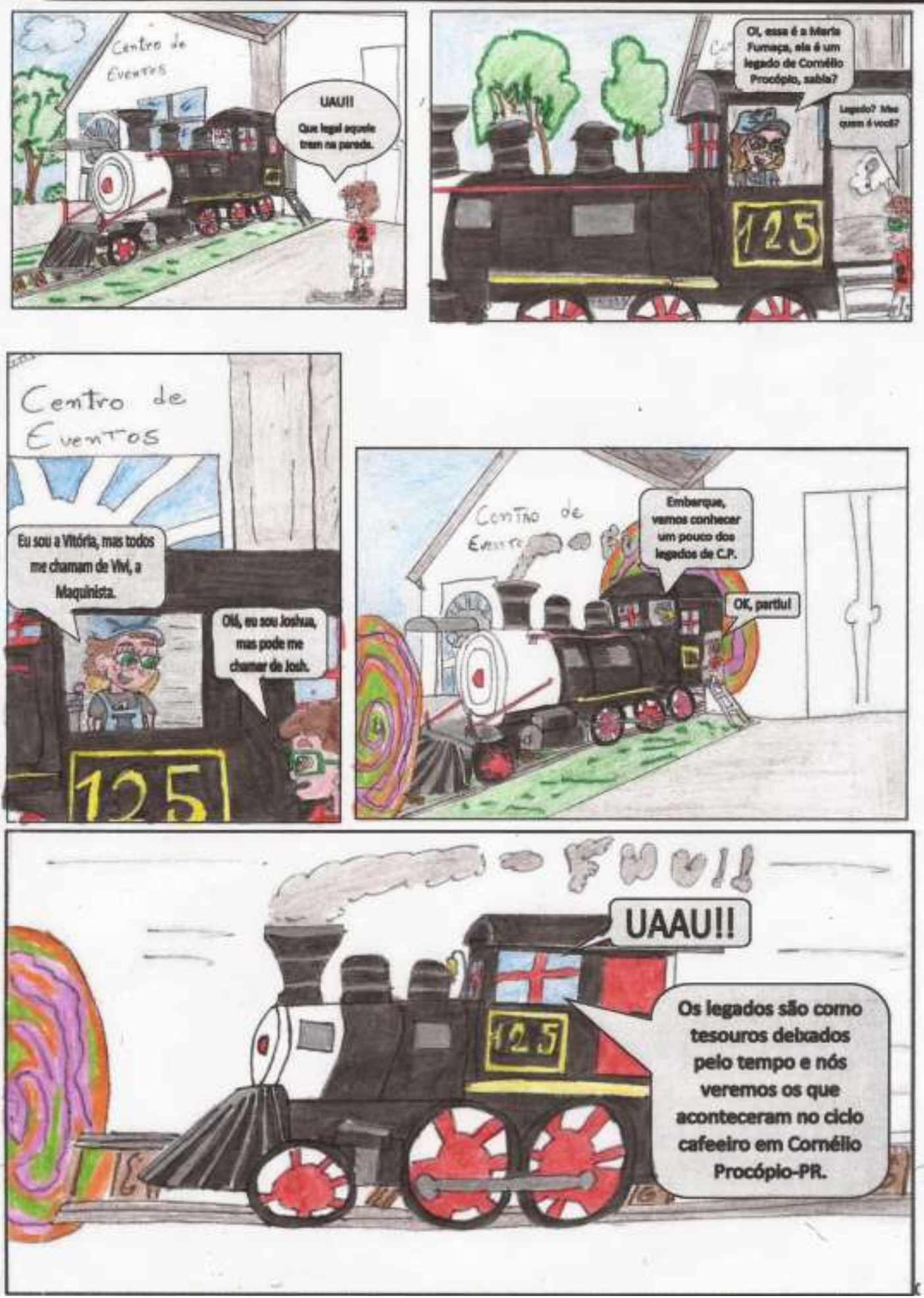

Autoria: Teixeira, 2018.

Dessa forma, como retratado na HQ's. "Vivi, a maquinista, e os legados do tempo de Cornélio Procópio", o assunto pode ser abordado em sala de um modo que não seja enfadonho aos alunos, de maneira que interajam e realizem análises, não somente do texto verbal, mas também da parte visual da história. 
Figura 6 - Segunda página HQ's: "Vivi, a maquinista, e os legados do tempo de Cornélio Procópio"
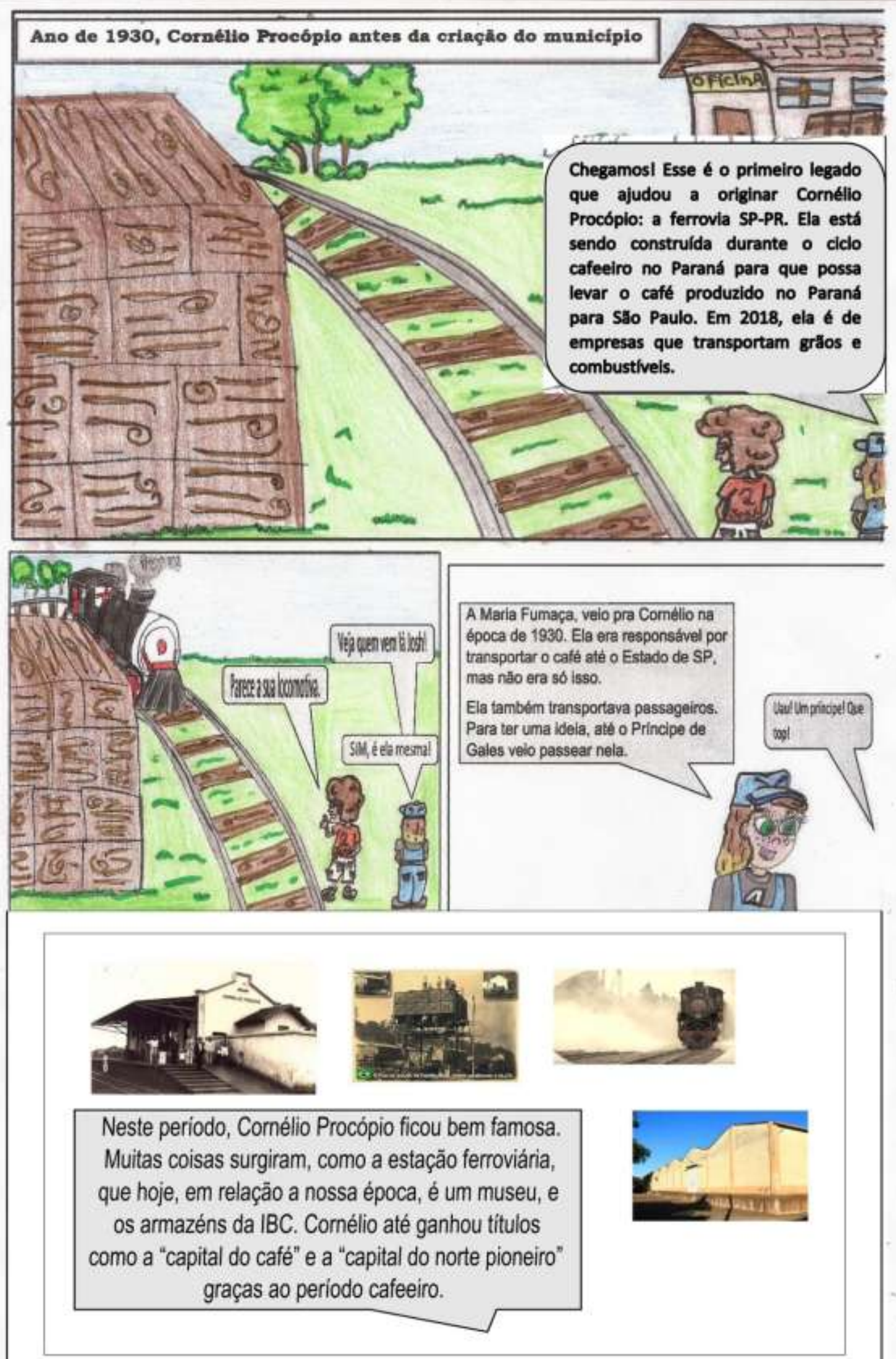

Autoria: Teixeira, 2018. 
Figura 7 - Terceira página HQ's: "Vivi, a maquinista, e os legados do tempo de Cornélio Procópio"

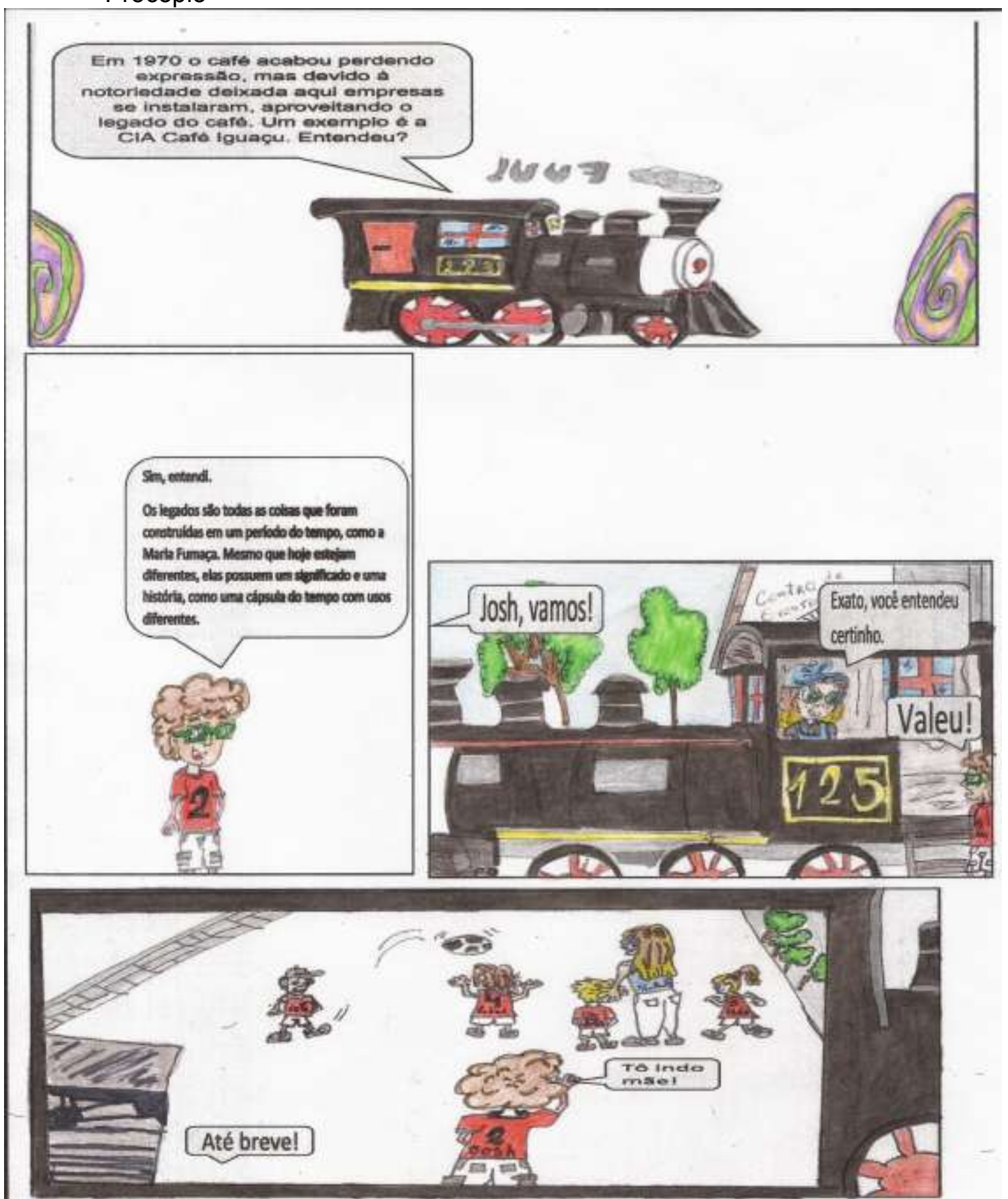

Autoria: Teixeira, 2018.

Para aqueles que têm dificuldade de assimilar o que está sendo tratado como legado, no caso as estruturas urbanas construídas durante o ciclo cafeeiro em Cornélio Procópio, podem visualizá-lo por meio da ilustração, a qual tem a capacidade de remeter o discente ao local e ao tempo que está sendo abordado e possibilita que o aluno aprenda a olhar para tais estruturas relacionando-as com os períodos de formação do território de sua vivência. 
Métodos e metodologias lúdicas demonstram-se importantes para a formação dos discentes, desde os tempos remotos, como disserta Comênio em sua obra "Didática Magna", acerca do discurso de Lutero.

Que sejam instruídos com o método mais fácil, não só para que não se afastem dos estudos, mas até para que eles sejam atraídos como para verdadeiros deleites, para que as crianças experimentem nos estudos um prazer não menor que quando passam dias inteiros a brincar com pedrinhas, bolas e corridas (COMÊNIO, 1957, p. 156).

As considerações feitas por Comênio (1957) sobre a fala de Lutero ressaltam a importância de se utilizar materiais lúdicos para o ensino dos discentes, para que se possa diminuir o cunho enfadonho de disciplinas como a Geografia. Esses materiais, métodos e metodologias devem estar ligados ao cotidiano desses alunos para que se desenvolvam "brincando". Desse modo, as histórias em quadrinhos colaboram para o emprego desse aspecto lúdico, em que a Geografia, apropriando-se deste gênero textual, fornece uma aula estimulante e prazerosa a esses discentes, auxiliando-os, assim, na aprendizagem e no desenvolvimento crítico.

\section{CONSIDERAÇÕES FINAIS}

O ciclo cafeeiro, bem como outros períodos históricos, tende a projetar no território produtos de representação que se cristalizam na infraestrutura urbana e social, demonstrando os graus de importância que esse ciclo teve para o município. Essas impressões são conhecidas como legados, que ao passar dos anos ganharam novas finalidades, sem perder a essência do produto original, que ficou inserido na estrutura urbana remetendo ao ciclo cafeeiro e a importância que esses legados tiveram para a formação do município de Cornélio Procópio.

Por diversas vezes, esses legados são mal compreendidos pela comunidade, ficando a mercê de depredações que acabam ocorrendo pelo abandono das gestões públicas. Isso se volta às questões da academia, a qual deve realizar estudos e levantar meios para conscientizar a comunidade da importância dessas estruturas.

A HQ's apresentada neste trabalho auxilia o professor de Geografia a elucidar a influência do período cafeeiro nas estruturas de Cornélio Procópio, para uma maior compreensão por parte do público discente, que por sua vez aprende a como analisar o espaço em que vive e as ações formadoras desses territórios, em que tudo se encontra conectado. Dessa forma, conota-se a importância que teve o ciclo cafeeiro no Paraná para Cornélio Procópio e como se configurou o território no qual hoje se localiza o município, deixando impressões em diversas esferas de sua estrutura. 
Assim, esta pesquisa mostra-se de grande valia para o professor de Geografia, por conta da problemática de se ensinar determinados conteúdos complexos para os alunos, de modo que esta forma metodológica de se abordar o conteúdo traz aos alunos a aproximação real e lúdica dos espaços que eles observam em seu cotidiano. Dessa maneira, facilita a observação e análise crítica dessas estruturas que são fruto do ciclo cafeeiro em Cornélio Procópio, cristalizadas no tempo.

\section{REFERÊNCIAS}

BRAGUETO, C. R. O comportamento territorial do norte do Paraná como frente de expansão e frente pioneira. In: CARVALHO, M. S. de; FRESCA, T. M. (org.). Geografia e norte do Paraná: um resgate histórico. Londrina: Humanidades, 2007. p. 141-199.

BRASIL, Á. S. Cornélio Procópio: das origens e da emancipação do município. Cornélio Procópio: UENP, 2014.

CABRAL, L. M.; SÁ, A. C. Instituto Brasileiro do Café (IBC). Rio de Janeiro, RJ: CPDO/FGV, 2009. Disponível em: http://www.fgv.br/cpdoc/acervo/dicionarios/verbetetematico/instituto-brasileiro-do-cafe-ibc. Acesso em: 21 mar. 2019.

CALLAI, H. C. Educação geográfica: ensinar e aprender geografia. In: CASTELLAR, S. M. V.; MUNHOZ, G. B. (org.). Conhecimentos escolares e caminhos metodológicos. São Paulo: Xamã, 2012. p. 73-87.

CARNEIRO, G. Cornélio Procópio lança concurso de ideias para revitalizar espaços do IBC. Folha de Londrina, Londrina, 19 jun. de 2018. Folha Norte Pioneira. Disponível em: https://www.folhadelondrina.com.br/norte-pioneiro/cornelio-procopio-lanca-concurso-deideias-para-revitalizar-espacos-do-ibc-1009042.html. Acesso em: 13 ago. 2018.

CASTELLAR, S. M. V. Educação geográfica: teorias e práticas docentes. São Paulo: Contexto, 2005.

CAVALCANTI, L. de S. A geografia escolar e a cidade: Ensaios sobre o ensino de geografia para a vida urbana cotidiana. Campinas: Papirus, 2008.

COMÊNIO, J. A. Didática magna. Lisboa: Fundação Calouste Gulbenkian, 1957.

COMPANHIA MELHORAMENTOS DO NORTE DO PARANÁ. Colonização e desenvolvimento do Norte do Paraná. Jussara, PR: CMNP, 1975. Disponível em: http://www.cmnp.com.br/melhoramentos/50anos-cmnp/files/CMNP.pdf. Acesso em: 15 jun. 2018.

DORFMUND, L. P. Geografia e história do Paraná. São Paulo: Editora do Brasil, 1962.

EISNER, W. Quadrinhos a arte sequencial. São Paulo: Martins Fontes, 1995.

FRESCA, T. M. A estrutura da rede urbana do Paraná. In: CARVALHO, M. S de; FRESCA, T. M. (Org.). Geografia e Norte do Paraná: um resgate histórico. Londrina: Humanidades, 2007. p. 201-250. v. 2.

HAESBAERT, R. O mito da desterritorialização: do "fim dos territórios" à multiterritorialidade. Rio de Janeiro: Bertrand Brasil, 2004.

IBGE. Cidades. Cornélio Procópio. História. 2017. Disponível em: https://cidades.ibge.gov.br/brasil/pr/cornelio-procopio/historico. Acesso em: 21 mar. 2019.

IPARDES - INSTITUTO PARANAENSE DE DESENVOLVIMENTO ECONÔMICO E SOCIAL. Caderno estatístico município de Cornélio Procópio. Brasília, DF: IPARDES, 2019. 
http://www.ipardes.gov.br/index.php?pg_conteudo=1\&cod_conteudo=30. Acesso em: 30 abr. 2019.

LUZ, F. O fenômeno urbano numa zona pioneira: Maringá, PR: Prefeitura de Maringá, 1997.

MACCLOUD, S. Desvendando os quadrinhos: história, criação, desenho, animação e roteiro. São Paulo: M. Books, 1995.

MARQUES, J. M. S. O clima, a vegetação e a hidrografia. In: SCORTEGAGNA, A.; REZENDE, C. J.; TRICHES, R. I. (org.). Paraná espaço e memória: diversos olhares histórico-geográficos. Curitiba: Bagozzi, 2005. p. 34-55.

MELO. F. P. de.; MELO E SOUZA, R. (Re)pensando o ensino de geografia e seus mitos. Revista Saberes, Paripiranga, BA, v. 1, n. 6, p. 2-10, maio/ago. 2018.

MELO. F. P. de; MELO E SOUZA, R. Reterritorialização do espaço agrário pernambucano, a partir de políticas públicas governamentais em Garanhuns-PE: erradicação do café e implantação da bacia leiteira. 2015. Disponível em: http://www2.fct.unesp.br/nera/artigodomes/6artigodomes_2015.pdf. Acesso em: 21 mar. 2019.

OLIVEIRA, S. C. de. Ciclos econômicos da erva-mate e do café. In: SCORTEGAGNA, A.; REZENDE, C. J.; TRICHES, R. I. (org.). Paraná espaço e memória: diversos olhares histórico-geográficos. Curitiba: Bagozzi, 2005. p. 204-227.

RAFFESTIN, C. Por uma geografia do poder. São Paulo: Ática, 1993.

RATZEL, F. Geografia do homem (antropogeografia). In: MORAES, A. C. R. (org.). Ratzel. São Paulo: Ática, 1990. p. 32-107.

SANTOS, M. A natureza do espaço: técnica e tempo: razão emoção. São Paulo: Hucitec, 2002.

SANTOS, M. Território e dinheiro. Revista GEOgraphia, Niterói, v. 1, n. 1, p. 7-13, 1999.

SAQUET, M. A. Estudos territoriais: os conceitos de território e territorialidade como orientação para uma pesquisa científica. In: FRAGA, N. C. (org.). Territórios e fronteiras: (re) arranjos e perspectivas. Florianópolis: Insular, 2011. p. 37-54.

SCORTEGAGNA, A. A geologia, o relevo e os recursos minerais. In: SCORTEGAGNA, A.; REZENDE, C. J.; TRICHES, R. I. (org.). Paraná espaço e memória: diversos olhares histórico-geográficos. Curitiba, PR: Bagozzi, 2005. p. 12-33.

SIMÕES DE PAULA, E. Cornélio Procópio. In: CARVALHO, M. S. de; FRESCA. T. M. (Org.). Geografia e norte do Paraná: um resgate histórico. Londrina: Humanidades, 2007. p. 23 49. v. 1.

VASCONCELOS, L. H. C.; PIRES, F. J.; LUZ, C. E. Origens e formação de Cornélio Procópio como cidade de transporte. 2014. Disponível em: http://www.cbg2014.agb.org.br/resources/anais/1/1403912669_ARQUIVO_artigo_cbg_finaliz ado.pdf. Acesso em: 15 jun. 2018.

VESENTINI, J. W. Geografia crítica e ensino. In: OLIVEIRA, A. U. de; BRABANT; J-M.; VESENTINI, J. W.; VLACH, V. R. F.; SANTOS, D.; CARVALHO, M. B. de; MORAES, A. C.; WETTSTEIN, G. (org.). Para onde vai o ensino de geografia? São Paulo: Contexto, 2003. p. 30-38.

WACHOWICZ, R. História do Paraná. Curitiba: Imprensa Oficial do Paraná, 2001.

Recebido: dezembro de 2018. Aceito: maio de 2019. 